Roberto Vettor

Jasna Prpić-Oršić

Carlos Guedes Soares

http://dx.doi.org/10.21278/brod69402

ISSN 0007-215X

eISSN 1845-5859

\title{
IMPACT OF WIND LOADS ON LONG-TERM FUEL CONSUMPTION AND EMISSIONS IN TRANS-OCEANIC SHIPPING
}

UDC 629.5.017.2:629.544

Original scientific paper

\begin{abstract}
Summary
The influence of weather conditions on fuel consumption and $\mathrm{CO}_{2}$ emissions for a containership is assessed by calculating the total added resistance, for various sea-states and relative wave directions, through a time domain procedure. The present article extended a formerly published research presented during the IMAM2015 conference [1] providing a deeper insight of the methodology adopted furtherly discussing the results achieved. In particular, the present paper studies the impact of wind velocity and directionality on the ship speed and its relative importance when compared with the wave added resistance. Moreover, considering the most commonly sailed routes in the North Atlantic, the long-term rate of increment of fuel consumption and $\mathrm{CO}_{2}$ emissions is estimated comparing the resulting ship performance with the wave climate expected for these specific routes.
\end{abstract}

Key words: $\quad$ fuel consumption; emissions; wind loads; speed loss; containership.

\section{Introduction}

The demand of international trades is expected to continuously increase in the next years, and so will the relevance of maritime shipping for the global economy and its burden on the ecosystems. In the last decade, the International Maritime Organization (IMO) promoted the exploration of solutions aimed at limiting the air pollution caused by ships in terms of a reduction of emissions of greenhouse gasses (GHGs). Possibilities of effective interventions have been identified both in the design and in the operational phases. As a consequence two indices have been developed to serve as a reference for monitoring the emissions and stimulating to pursue innovative solutions. The Energy Efficiency Design Index (EEDI, [2]) is a measure of the ship's energy efficiency and relates the $\mathrm{CO}_{2}$ emissions to a nominal transportation work rate depending on the ship type and technical characteristics. In the Energy Efficiency Operational Indicator (EEOI, [2]), instead, the efficiency of a specific voyage is calculated by comparing the emissions to the effective cargo carried and the length of the journey.

At the design phase, the energy efficiency can be improved through the optimization of speed and cargo capacity, propulsion system and the form of the hull and the superstructure, leading to reductions between $10 \%$ to $50 \%$. A similar improvement can be obtained in the operational phase by making weather routing, fleet management and efficient logistics be part 
of the daily activity of any ship operator. Overall emissions could be lowered of a rate that ranges between $25 \%$ and $75 \%$ if the two approaches are combined [3]. To ensure future maritime transportations to be cleaner, but also more competitive, a key role has to be played by the shipping industry, placing energy efficiency and environmental protection at a first place since the design phase.

Environmental loads are among the most important factors influencing the fuel consumption of a vessel in navigation. This is clearly shown in [4] where a fuel efficiency model is proposed from the analyzes of log data of container-ships. Not only ship resistance is increased due the effect of waves and wind on the hull and superstructures. Indeed, the efficiency of the propulsion system is also reduced, generally with the effect of requiring more power, decreasing the attainable ship speed and increasing the fuel consumption and emissions. Moreover, ship motions may induce the Shipmaster to voluntary reduce the speed, increasing the complexity of an accurate assessment of ship performance in seaways.

In the past ship design was often focused on meeting the requirements of the trial tests, thus the hull resulted optimized to navigate at the design speed in still water and at full load draft. Such a condition has an extremely low probability to be encountered in real operations. Instead, the ship will frequently be partially loaded, in some cases sailing at different speeds and, as shown in [5], in an environment far from the ideal still water.

A reliable estimation of the attainable ship speed in the actual environment that the ship will encounter is a critical task to support the decision making processes in the maritime economy. It is fundamental, among the others, for the selection of the most favorable route [6] and logistic issues, but also when comparing different designs. All the factors influencing the added resistance must be taken into account for an accurate estimation of ship efficiency on a seaway, as depicted in figure 1 where a scheme of the program is shown.

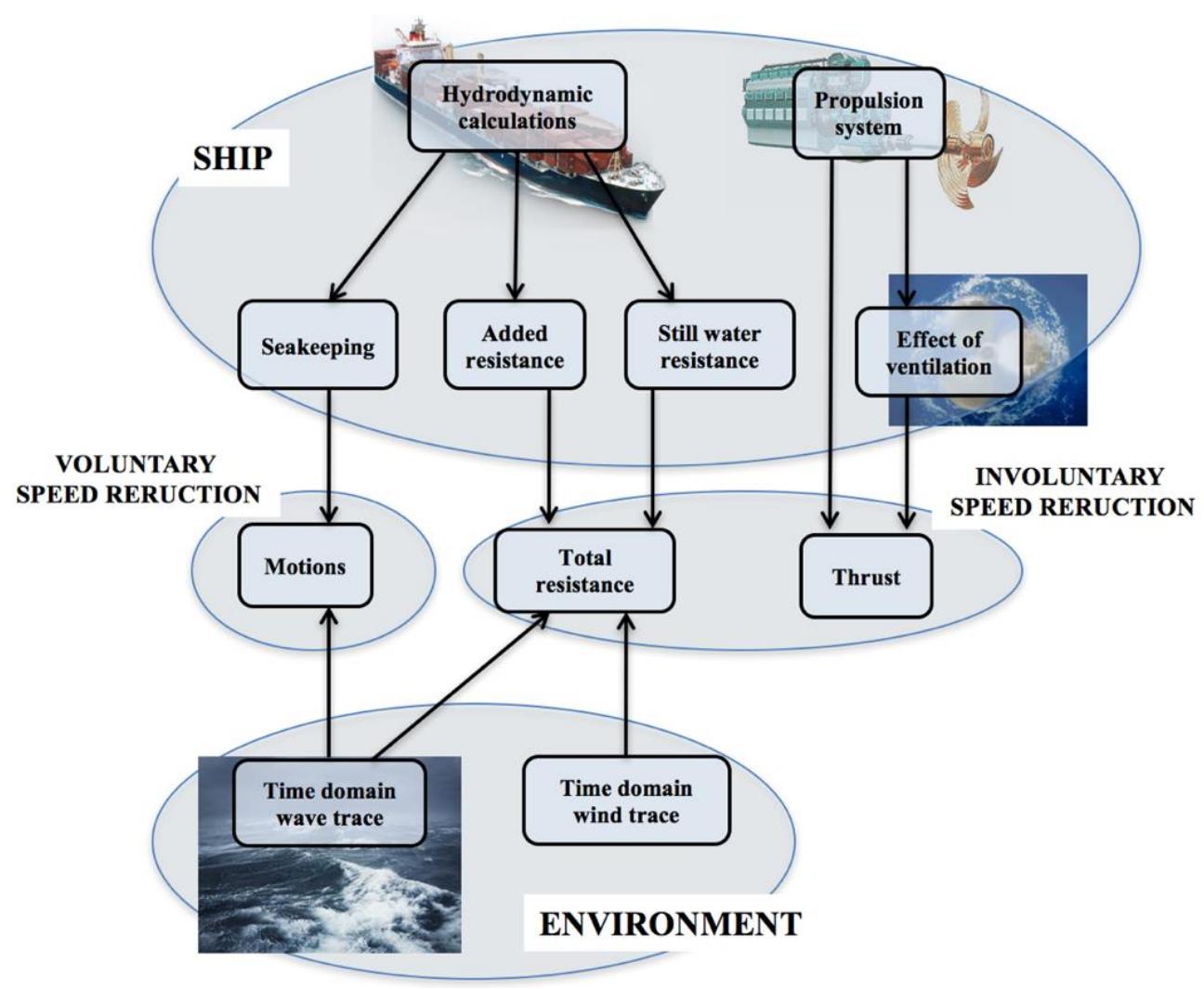

Fig. 1 Schematic code architecture 
The irregular sea and wind loads are simulated in the time domain for the specific sea state. While the effect of waves has been discussed in previous articles of the authors [7], [8], this work focuses on the effect of wind on the involuntary speed reduction, and on fuel consumption. Wind loads on marine structure have been largely studied in the literature. A review of the methods can be found in [9]. In most of the cases, wind is studied for its negative effect on safety and maneuverability [10], [11], especially on ships with large exposed surface when sailing in congested areas or in ports. The combined effect of wind and waves on attainable speed has been studied by [12] with an application to a bulk carrier. In [13] added resistance due to both wind and waves is considered to develop a semi-empirical performance prediction model. An estimation of the extreme wind loads can be found in [14], where four methods have been used to compute ahead force, a side force and the yawing moment. The statistical analysis of noon reports of ships with large exposed area (pure track or car carrier), has been performed by [15]. The fuel consumption and speed curves corresponding to different Beaufort have been estimated, showing an increase of the resistance of $1.6 \%$ in head wind compared to side wind. [16] showed that speed loss due to wind may be comparable to the one due to waves for high ship speeds and heavy weather conditions. [17] assessed the resistance and consumption due to wind to account for up to one third of the total ones in challenging weather conditions.

In this paper, the impact of wind loads on the speed loss and fuel consumption is estimated in the time domain considering a pre-defined initial cruise speed and the forces acting on the superstructures due to a simulated realistic wind profile. the attainable ship speed in a given condition is then assessed as the mean values of the resulting ship speed time-series. In section 2 methodology adopted for the simulation of a realistic wind time-series is presented. Section 3 describes the computation of the wind load on the hull above the sea level and the superstructure, and of the effect on the propulsion system. Section 4 underlines the method used to assess the long-term effect of wind in a seaway. The application of the method to a containership is shown in section 5, providing a quantitative assessment of the relevance of wind in the speed drop when compared to waves. Conclusions and final remarks are discussed in section 6.

\section{Wind time series simulation}

The program allows to compute the ship speed in time affected by a fluctuating wind profile. This is obtained by superposing a turbulent (gust) component to the mean speed, aiming at realistically reproduceing the actual condition encountered by a ship. Thus, the generation of the wind trace is fundamental for a reliable estimation of attainable speed and, consequently, fuel consumption.

The horizontal component is described by the mean direction, the mean speed, and its fluctuation aiming at capturing the stochastic nature of wind, continuously varying in time and space. Instead, the vertical component of wind velocity is usually neglected in practical applications.

For a given mean speed, the fluctuation can be represented as a random process with zero mean, distributed in frequency according to a spectrum called the gust spectrum. The description of such a turbulent process is very complex task, which has been largely studied in the literature in order to represent the fluctuating component in terms of a gust spectrum. Proposed formulations include among the others: the Harris (1971) spectrum [18], the Davenport spectrum [19] that derives from measurements on land, [20], [21] and NPD Wind [22]. The program, initially developed in [7] has been extended to include the effect of wind according to the previous considerations. The code supports the calculation of the gust component by applying the formulations of Harris or Davenport. 


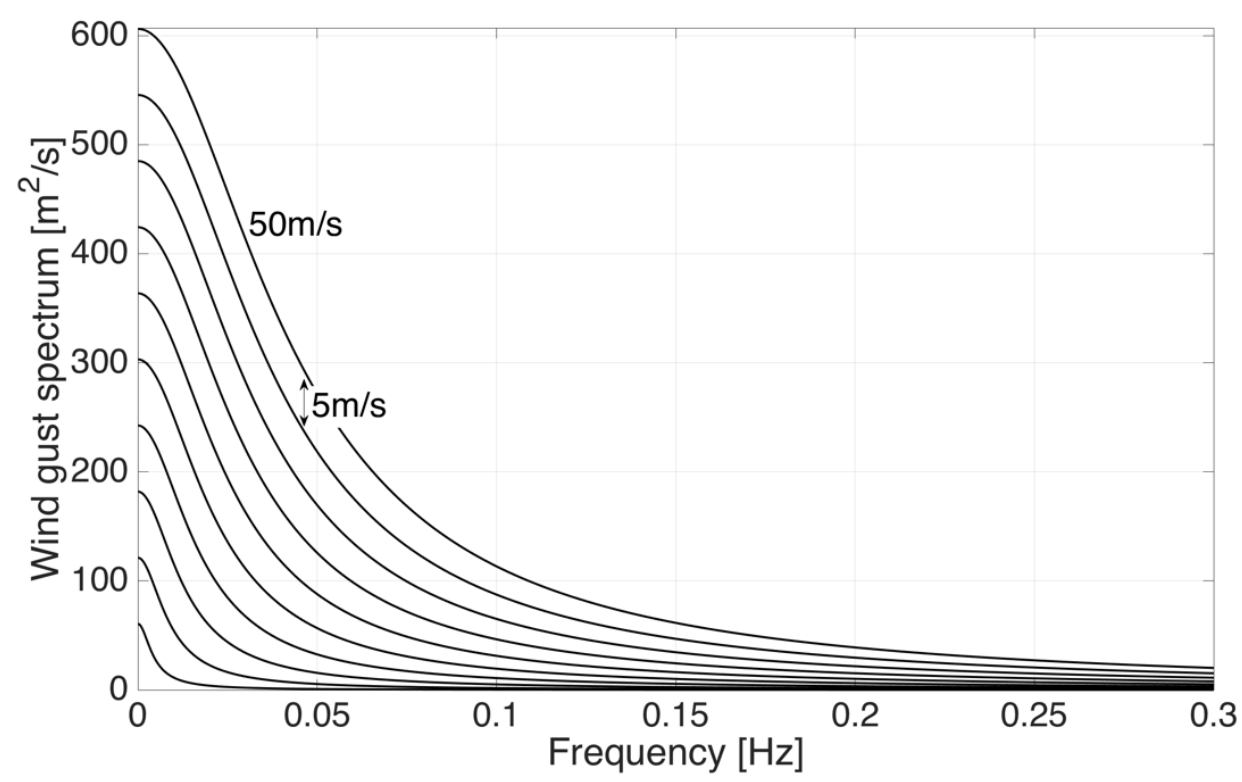

Fig. 2 Harris gust wind spectra for different mean wind speeds

The Harris formulation has been chosen for the simulation of the wind gust, as recommended by the registers for the design of offshore structures [23]:

$$
f \cdot \mathrm{S}(f)=4 \kappa \bar{U}^{2} \frac{f^{\prime}}{\left(2+f^{\prime 2}\right)^{5 / 6}}
$$

where $S$ indicates the power spectral density $\left[\mathrm{m}^{2} / \mathrm{s}\right], f$ is the frequency $[\mathrm{Hz}], \kappa$ is the surface roughness parameter and $f$ 'is the non-dimensional frequency given by:

$$
f^{\prime}=\frac{1800 f}{\bar{U}}
$$

The Harris wind gust spectra for different mean wind speed from $5 \mathrm{~m} / \mathrm{s}$ to $50 \mathrm{~m} / \mathrm{s}$ is shown in figure 2. The time series is then computed assigning a random phase to each frequency and the amplitude computed as:

$$
z(f)=\sqrt{2 S(f) \Delta f}
$$

Figure 3 shows three samples of simulated wind trace of the duration of 10 minutes. Mean speeds of $6.9 \mathrm{~m} / \mathrm{s}, 15.3 \mathrm{~m} / \mathrm{s}$ and $26.5 \mathrm{~m} / \mathrm{s}$ respectively are considered, corresponding to the significant wave heights of $1 \mathrm{~m}, 5 \mathrm{~m}$, and $15 \mathrm{~m}$ when the Pierson-Moskowitz relation is assumed.

\section{Wind loads}

Among the environmental loads, wind may give a not negligible contribution, especially in particular conditions of speed and relative direction and for ships with great area above the waterline. From the safety point of view, criticalities are in most of the cases limited to maneuvering or mooring in locations characterized by strong winds and narrow passages. However, a reliable assessment of the attainable speed may also require to take into account the influence of wind.

In regular operations, its influence is generally constrained to an added resistance, that may be positive in case of following wind, and a drift component. Although the drift component may require to adjust the route with an appropriate rudder angle, resulting in increased consumptions, hereafter only the direct influence on added resistance will be taken into account. 


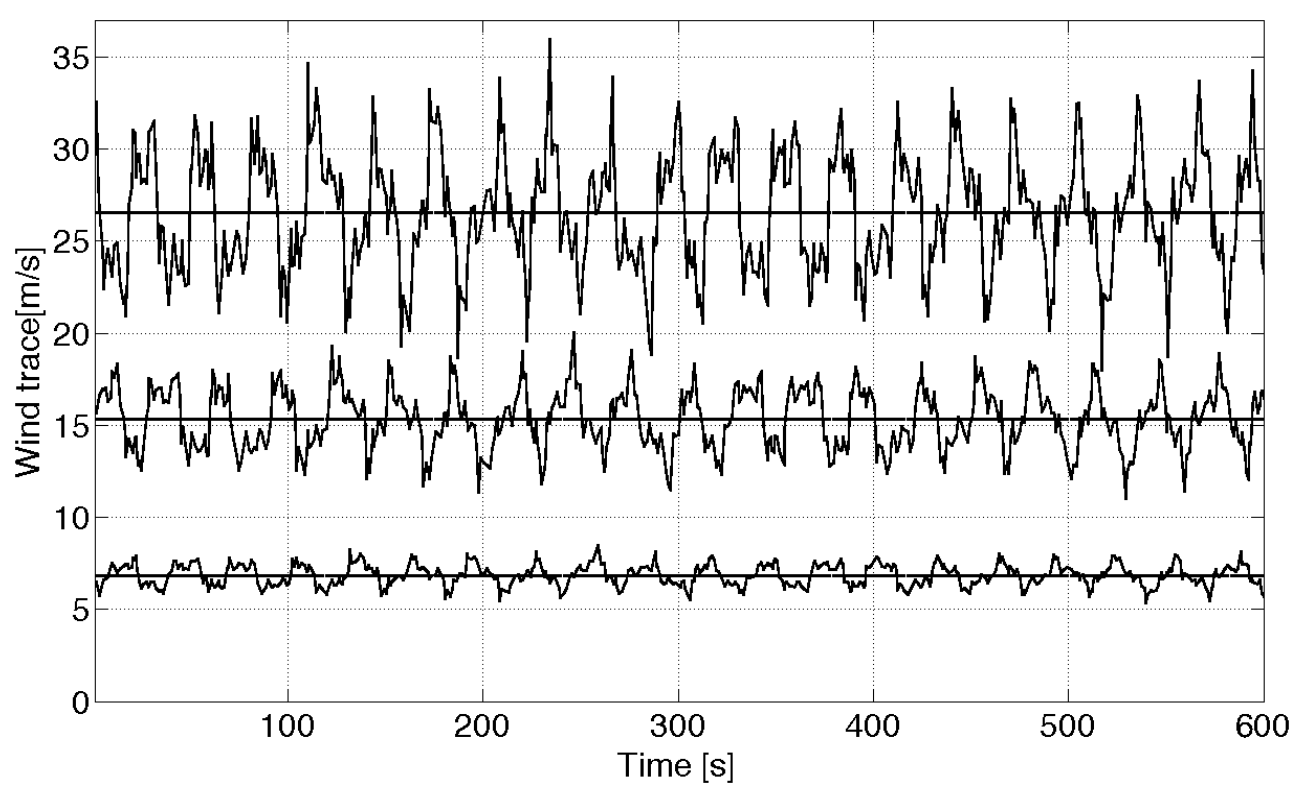

Fig. 310 minutes wind time-series corresponding to mean speeds of $6.9 \mathrm{~m} / \mathrm{s}, 15.3 \mathrm{~m} / \mathrm{s}$ and $26.5 \mathrm{~m} / \mathrm{s}$

A thorough mathematical model can be found, for instance, in [10].

Equation 4 can be applied for the calculation of the longitudinal force imposed by wind:

$$
F_{\text {wind }}=\frac{1}{2} C_{X W} A_{T} \rho_{\text {air }} U_{\text {rel }}^{2}
$$

where $C_{X W}$ is the aerodynamic drag force coefficient, $A_{T}$ is the frontal wind exposed area, $\rho_{a i r}$ is the air density and $U_{r e l}$ is the relative wind speed. The increased ship resistance due to the rudder correction necessary to keep the course has been neglected.

The area above the sea-level is typically not considered when tank tests or wave added resistance numerical software which provide information on hull resistance. Nevertheless this exposed area is affected by presence of the wind that, due to the forward ship speed, exist even in the mildest weather conditions. Due to this self-component, both speed and direction of the natural wind must be adjusted when calculating the wind as seen by the ship. In figure 4 a schematic representation of absolute and relative wind direction is provided.

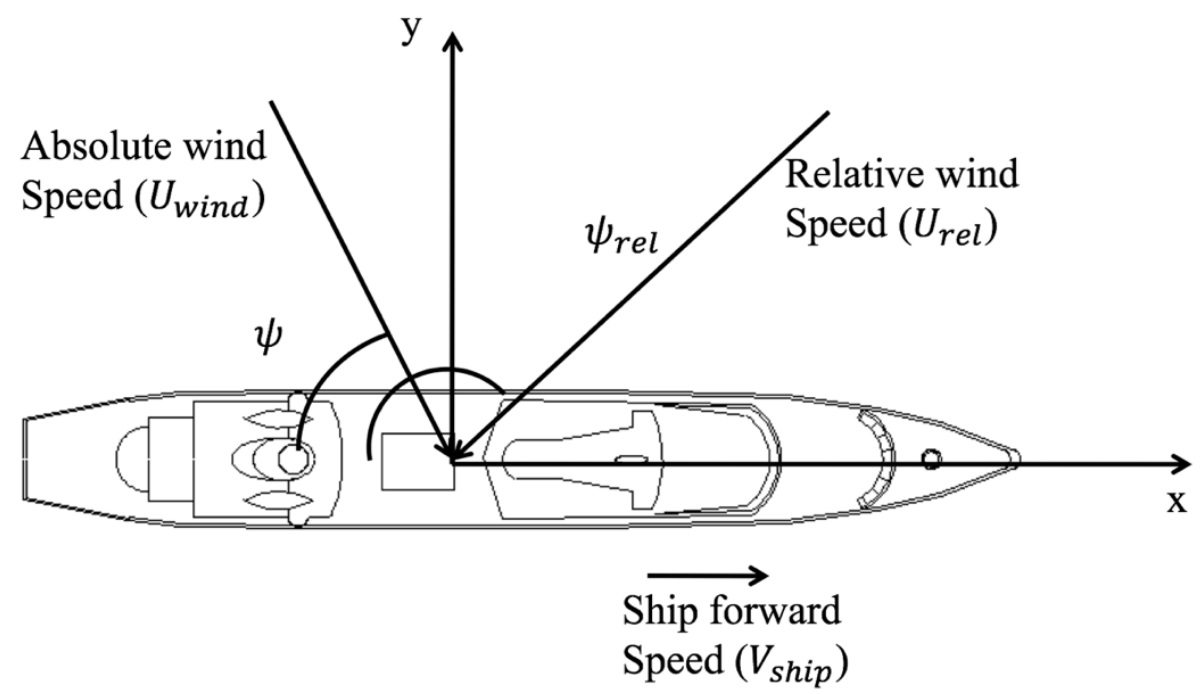

Fig. 4 Schematic representation of the relative wind 
For the computation of the relative wind speed and direction (by convention zero corresponds to following wind) the following equations can be applied:

$$
\begin{aligned}
& U_{r e l}=\sqrt{\boldsymbol{u}_{r e l}^{2}+\boldsymbol{v}_{r e l}^{2}} \\
& \psi_{r e l}=\operatorname{atan2}\left(\left|\boldsymbol{u}_{r e l}\right|,\left|\boldsymbol{v}_{r e l}\right|\right)
\end{aligned}
$$

where $\boldsymbol{u}_{r e l}$ and $\boldsymbol{v}_{r e l}$ are the longitudinal and lateral component respectively given by the equations:

$$
\begin{aligned}
& \left|\boldsymbol{u}_{\text {rel }}\right|=-U_{\text {wind }} \cos (\psi-\pi)-V_{\text {ship }} \\
& \left|\boldsymbol{v}_{\text {rel }}\right|=U_{\text {wind }} \sin (\psi)
\end{aligned}
$$

Equation 4 moves the problem of calculating aerodynamic force to the critical estimation of the drag force coefficient $C_{X W}$. Albeit wind tunnel tests (e.g. [24]) are recommended for accurate results, such trials are typically expensive and time consuming. CFD calculations are nowadays possible alternatives [25], nevertheless factors such as the relative direction, the ship draft and the cargo distribution (e.g. in a containership), as well as the relative direction, have an influence on $C_{X W}$, as shown in [26]. Thus, the applicability of these methodologies to operative problems is limited.

For practical application one can opt to a faster numerical formulation for the estimation of the wind loads. In literature numerous proposals can be found:

- Gould [27], [28] studied effect of wind on the superstructures considering a logarithmic wind profile, aiming at the development a procedure for the estimation of the resulting forces and moments.

- Isherwood [29] based his analysis on several results published in literature relative to a wide range of ships and relative directions and introduced regressions providing lateral and side wind forces and yaw moment.

- Blendermann [30], [31] performed various wind tunnel tests on scale model systematically collecting the results. The statistical analysis of such a database permitted the formulation of expressions to relate wind drag force coefficients (for both forces and moments) to the frontal and lateral projected areas depending on the angle of attack of wind.

- The OCIMF method [32] is suitable for very large crude carriers (VLCCs) and has been developed from statistics on a database of wind tunnel tests.

It is necessary to remember that, while the previous methods can provide an indication for standard cases, in critical situations it is recommended to verify them with experiments. Indeed, often the outcomes are not in agreement as they derive from different assumptions and databases, as shown in [9] where a comparative study is performed.

Isherwood method is used in the this work to estimate the drag force coefficient for the wind directions from $0^{\circ}$ to $180^{\circ}$ with a step of $30^{\circ}$ (see table 2). A spline interpolation is then applied to take into account the actual relative direction at each step.

According to the method proposed by [29], the drag force coefficient can be readily estimated when knowing a number of dimensions of the ship: the overall length $L_{O A}$, the beam $B$, the lateral and transverse projected $A_{L}$ and $A_{T}$, the length $S$ of the perimeter of the lateral projection excluding waterline and slender bodies, the distance from bow of the centroid of the lateral projected area $C$ and the number of distinct groups of masts or kingposts. Thus, the coefficient is given by the equation:

$$
C_{X W}=A_{0}+A_{1} \frac{2 A_{L}}{L_{O A}^{2}}+A_{2} \frac{2 A_{T}}{B^{2}}+A_{3} \frac{L_{O A}}{B}+A_{4} \frac{S}{L_{O A}}+A_{5} \frac{C}{L_{O A}}+A_{6} M
$$


The actual speed that the ship is able to sustain is computed at each time-step comparing the thrust provided by the propeller and the total resistance including the variating wind force. A B-series propeller [33] is assumed and the required number of revolution (RPM) is calculated according to the relative torque characteristics and the wake fraction. A constant engine torque is considered by accounting for the mass inertia of the ship and engine performance.

Depending on the difference between the initial and the attainable speed, the system may take some cycles to reach a stationary condition, from where the mean speed can be considered as representative of the attainable speed. In [7] more details on the model are provided.

\section{Effect on a seaway}

The model for the calculation of the forces that wind imposes to the ship has to be matched with appropriate weather information depending on the purpose. If the estimation of wind effect on a near future route is required, output of a numerical weather forecast has to be used. Differently, considering a historical weather database allows assessing the long-term effect (see [34]). In the following the second approach is adopted.

A wave database contains climatological data in a spatial grid covering a specific area, which can be obtained from simulation models, measurements or observations. The state of the art wave models [35], [36] allow to solve the spectral energy equation and assess how the directional wave spectrum propagates in space and time. Due to the continuous evolution of both numerical models and data assimilation schemes differences in the long-term results may in some cases be related to these changes rather than to the natural variability of weather. In order to allow comparisons and significant statistics for a specific long period of time, weather databases are generated by running the same model over the desired period as to overcome the numerical inhomogeneities. Such a process is called reanalysis [37]. It must be noted that the issue of differences in measured data coverage over time cannot be solved.

The state-of-the-art product ERA-interim reanalysis [38] from the European Centre for Medium-Range Weather Forecast (ECMWF) is used in this work. The database has been generated from 1979 and is updated in real time, covering the entire globe. Besides atmospheric variables, the ERA-Interim also includes wave parameters, produced using the ECMWF Integrated Forecasting System by a two-way coupled atmosphere-wave model system. The wave model used is the WAM model with a four-dimensional Variational Data Assimilation (4DVAR) scheme. Observations of ocean wind speeds from VOS, buoys, satellite scatterometer and (when available) satellite altimeter SWHs were assimilated in the analysis process. The database consists of 6-hourly global fields with a $1^{\circ} \times 1^{\circ}$ grid resolution for the wave parameters. Figure 7 shows the global mean SWH computed from the ERA-interim database.

The statistical multivariate distribution of all variables involved in the process is calculated from the ERA-interim database. When only the wind is considered it reduces to the bivariate distribution of mean wind speed and direction. Instead, when the effect of waves is also included, it becomes a five-variate distribution of significant wave height $\left(\mathrm{H}_{\mathrm{S}}\right)$, wave peak period $\left(\mathrm{T}_{\mathrm{P}}\right)$, mean wave direction $\theta$, mean wind speed $\left(\mathrm{W}_{\mathrm{S}}\right)$ and direction $\left(\mathrm{W}_{\mathrm{D}}\right)$. In this work a different probability distribution has been calculated for each one of the routes analysed considering the effective climate on their path, making the results more detailed.

When both wind and waves are taken into account, the long term influence on the speed reduction is computed assuming the superposition of the effects, such as:

$$
\Delta \mathrm{V}=\sum_{H_{S}, T_{P}, \theta, W_{S}, W_{D}}\left[p_{i}\left(\Delta \mathrm{V}_{H_{S}, T_{P}, \theta}+\Delta \mathrm{V}_{W_{S}, W_{D}}\right)\right]
$$

where $\Delta \mathrm{V}_{H_{S}, T_{P}, \theta}$ and $\Delta \mathrm{V}_{W_{S}, W_{D}}$ are the speed drops due to waves and wind respectively and $p_{i}$ is the probability of encountering the specific weather condition. 
Knowing the attainable speed of the ship, the average fuel consumption on the seaway is given by:

$$
\mathrm{FOC}=C_{\text {conv }} \cdot \frac{S F O C \cdot B P}{V} \cdot L_{\text {route }}
$$

where SFOC is the specific fuel oil consumption in $\mathrm{g} / \mathrm{kWh}, \mathrm{BP}$ is the engine brake power in $\mathrm{kW}, \mathrm{V}$ is the ship speed in knots, $L_{\text {route }}$ is the length of the route in nautical miles and $C_{\text {conv }}=$ $10^{-6}$ is a conversion coefficient to obtain the FOC in metric tonnes.

Strictly, when the ship drag is increased, also the propeller load is increased, thus, if the engine torque is constant, the engine speed will drop meaning the engine power would also drop. Furthermore, every change would also result in the change of the SFOC. For slight changes, however, the engine working point does not undergo large variations, thus constant power condition may be assumed and the SFOC may be considered constant as well.

Being the present work focused on the long-term effect on fuel consumption and emissions rather than on operational or extreme conditions, the inaccuracy introduced do not have a significant impact on the results. Heavy weather conditions, in fact, are encountered very seldom due to the tendency of ship to avoid storms. As an example, in the most severe route considered (denoted as Ch_VA in figure 7), a ship has about $8 \%$ probability to encounter a significant wave height greater than $5 \mathrm{~m}$.

\section{Numerical example}

The S175 containership has been used to test the developed code. The cruise speed set as initial condition is 21 knots and requires from the main engine $27.5 \mathrm{MW}$ to be sustained in calm water. This condition corresponds to a fuel oil consumption (FOC) of $224 \mathrm{~kg} / \mathrm{nmi}$. In table 1 the main dimensions of the ship are listed, while the drag force coefficients calculated according to Isherwood method are shown in table 2.

In figure 5 the attainable ship speed for different relative direction is plotted in function of the absolute wind speed. When wind speed is moderate, namely lower than $6-8 \mathrm{~m} / \mathrm{s}$ the influence of the self-wind component caused by the ship speed is predominant. The impact of natural wind can be appreciated for stronger wind speeds, although in the considered conditions a decrease of 0.5 knots at most can be found.

Table 1 Main dimensions of the S175 containership

\begin{tabular}{lr}
\hline Length between perpendiculars & $175.0 \mathrm{~m}$ \\
\hline Breadth moulded & $25.4 \mathrm{~m}$ \\
\hline Design draft & $9.5 \mathrm{~m}$ \\
\hline Lateral projected area & $3710 \mathrm{~m}^{2}$ \\
\hline Transverse projected area & $756 \mathrm{~m}^{2}$ \\
\hline
\end{tabular}

Table 2 Aerodynamic drag force coefficient for different relative wind directions

\begin{tabular}{|l|l|}
\hline Wind dir. & $C_{X W}$ \\
\hline 0 & -0.136 \\
\hline 30 & -0.230 \\
\hline 60 & -0.146 \\
\hline 90 & -0.025 \\
\hline 120 & 0.192 \\
\hline 150 & 0.313 \\
\hline 180 & 0.146 \\
\hline
\end{tabular}




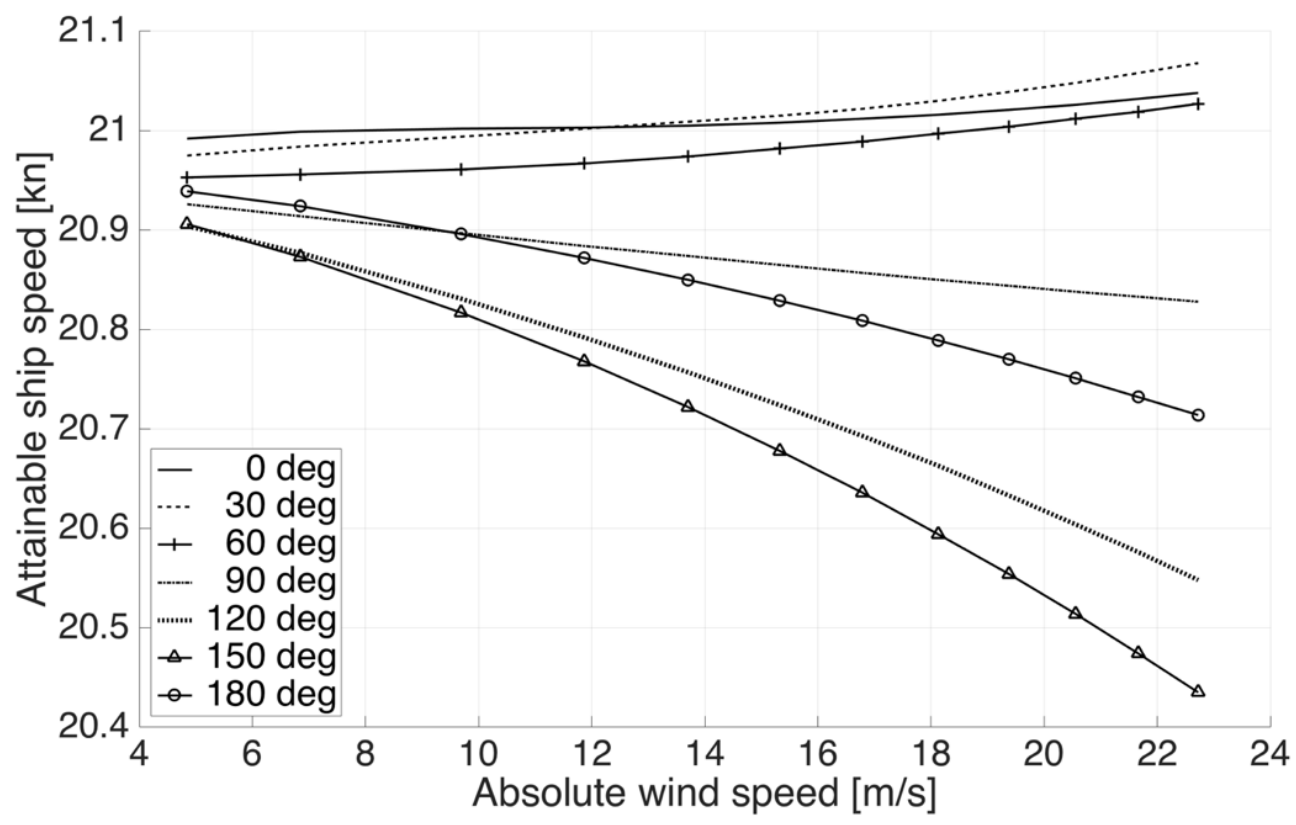

Fig. 5 Speed loss due to wind for different relative wind directions

The wind direction of $150^{\circ}$ is selected, being the direction from where wind has the most important effect on speed loss, to compare it with the effect of waves. The results are shown in figure 6 for wind and wave separately, as well as their combined effect [39].

The case of fully developed sea-states is considered, that is wind speed and SWH are considered correlated through the Pierson-Moskowitz relation, such as:

$$
\mathrm{SWH}=0.22 \frac{U_{\text {wind }}^{2}}{g}
$$

It is thus assumed that wind and waves are aligned, which is generally true for developing seas, but may be not the case in the open ocean on a swell dominated sea-state.

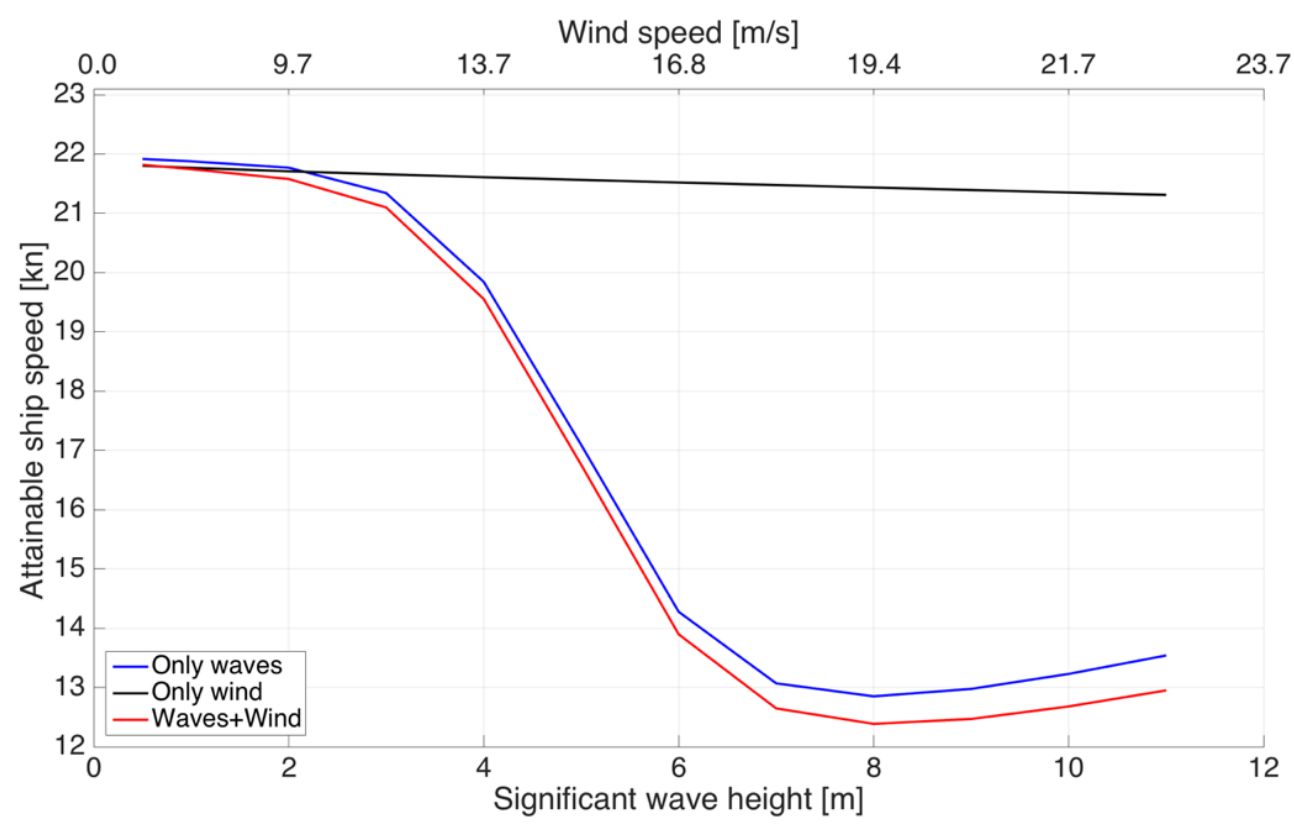

Fig. 6 Speed loss due to wind, waves and the combined effect for sea-states from $150^{\circ}$ 


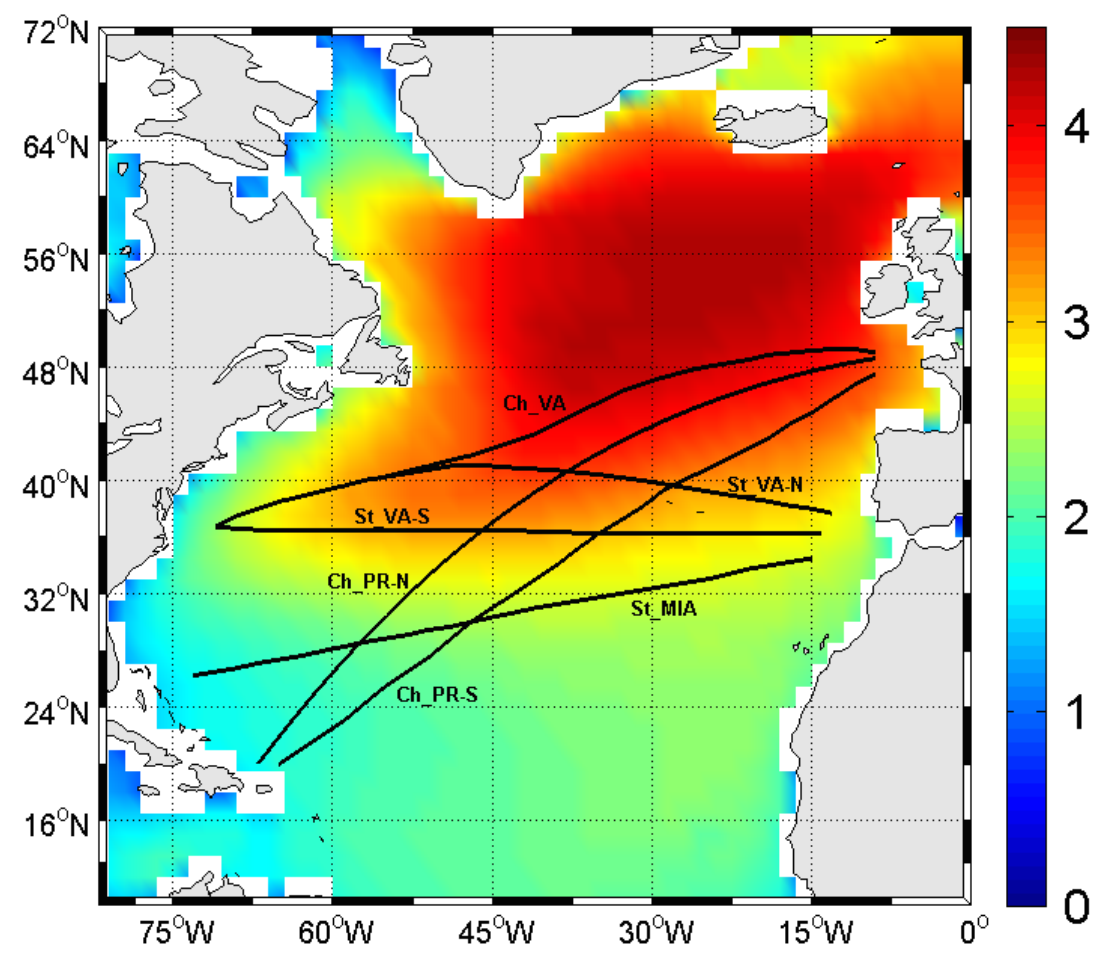

Fig. 7 Main North Atlantic routes (from [5]). Background colour shows the winter mean significant wave height (in meters).

The red and blue curves show a stabilization and small increase of the ship speed when $H_{S}$ exceeds 8 meters. The reason can be attributed to the use of a one parameter spectral model. When wave heights increase, wave periods does the same, eventually resulting in lower motions and loads on the hull.

Except for very low SWH, the wind effect on reducing ship speed in operations is in general minor when compared to the total environmental loads. This effect settles on values of about $6 \%$ for sea-states characterized by SWH higher than $5 \mathrm{~m}$.

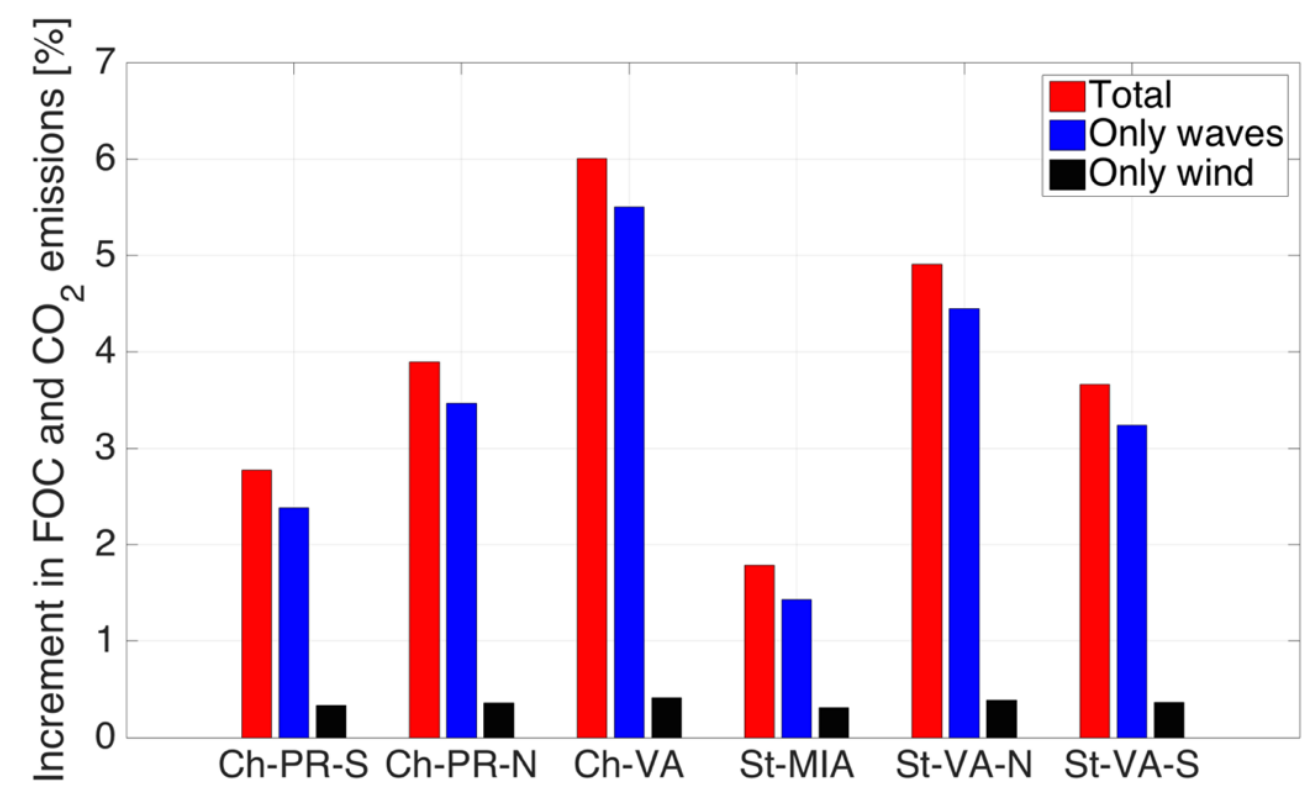

Fig. 8 Rate of increment of fuel consumption and $\mathrm{CO}_{2}$ emissions due to environmental factors in the main North Atlantic routes. 
A database derived from [40] has been here used for the estimation of the long-term effect on fuel consumption and $\mathrm{CO}_{2}$ emissions. It describes the real weather experienced by ships navigating on the routes identified in [5] and showed in figure 7. Figure 8 shows the results of such analysis in terms of percentage of increment, with respect to calm weather, caused by the wind. The sole effect of waves and the combination of both environmental factors are also given for comparison. The portion due to wind has an overall contribution of about $0.4 \%$ of increment of FOC, which, although small can be not negligible when detailed analysis is performed. Moreover, this rate refers to open waters, characterised by a significant predominance of swell or fully-developed sea-states. It can be expected to increase when routes on marginal seas are considered, such as Mediterranean or Baltic.

As it was expectable, northern routes, which include the areas where extratropical storms generate, are those more conditioned by environmental factors. In these cases, an increase of $6 \%$ in the FOC can be accounted in the long term. This is not the case for the southern routes and especially the one between the Strait of Gibraltar and Miami where the influence of weather is lower than $2 \%$.

\section{Conclusions}

The impact of wind load on ship speed loss, fuel consumption and $\mathrm{CO}_{2}$ emissions has been studied for different weather that ships may encounter. Furthermore, the long-term effect for some important trans-oceanic routes has been estimated.

For a given weather condition a realistic wind time-series is simulated by considering appropriate wind gust spectra. Then the ship speed is calculated in the time domain considering step by step the actual wind load affected by the relative speed and direction. Finally, the mean of the resulting speed profile is considered representative of the mean attainable speed. The long-term influence of environmental loads on speed reduction, fuel consumption and emissions is studied by considering the actual weather that a ship faces while sailing a specific route. For this purpose, the join probability of encountering determined weather conditions has been taken into account through the analysis of the climate which characterises the main North Atlantic routes.

Within $0^{\circ}$ and $60^{\circ}$, wind pushes the vessel and, in hypothetical calm waters, allows the conservation of the cruise speed and its minor increment for stronger winds (indicatively with speeds higher than $14 \mathrm{~m} / \mathrm{s}$ ). The worst conditions are for wind from $120^{\circ}$ and $150^{\circ}$ due to the loading of containers above the deck which extends the area exposed to wind, resulting in an increase of the drag force coefficient. Even in these cases, however, the speed drop is limited to less than one knot.

The increment in the fuel consumption and $\mathrm{CO}_{2}$ emissions only due to wind appears to be small. On the other hand, when it is neglected it leads to an underestimation of roughly $0.6 \%$, As a regerence, it means as much as 5 tonnes of fuel in a trans-oceanic passage as an average.

The results show that long-term effect of wind is much lower than the one of waves, and its low percentages may follow within the general uncertainties of environmental loads when considering the lifetime of a ship. Different results could come if specific operations are considered. For instance, for ships sailing in storms at low speed, in congested or restricted waters or in developing sea-states typical of marginal seas, a greater impact of wind can be expected.

In the present study wind speed and SWH are correlated according to the PiersonMoskowitz relation, that is fully developed sea-states are considered. Due to this assumption, the effect of wind in marginal seas or sheltered areas, where the occurrence of developing seas is higher, can be underestimated. To take into account these conditions, further studies 
excluding the strict dependency of wind and waves are necessary. Nevertheless, due to the high computational demand of such analysis with the time-domain program used, they have not been carried out in the present work.

The results confirm the expectations on the effect of wind loads and its proportion with respect to wave loads. Nevertheless, due to the minor relative influence of wind on speed loss, the differences between the approach presented in this paper and traditional methodologies is expected to be negligible. Taking into account the higher complexity of the technique here proposed, this is not expectable to supersede traditional methods which can be considered sufficiently reliable for the scope of ship operations.

\section{ACKNOWLEDGEMENTS:}

This work was performed within the project SHOPERA-Energy Efficient Safe SHip OPERAtion, which was partially funded by the EU under contract 605221 .

This work was also supported by the University of Rijeka (contract no. 13.09.1.1.05) and Croatian science foundation -project 8722.

The first author was supported by the Portuguese Foundation for Science and Technology (FCT - Fundação para a Ciência e Tecnologia, Portugal) under the contract no. SFRH/BD/89476/2012.

\section{REFERENCES}

[1] R. Vettor, J. Prpić-Oršić, and C. Guedes Soares, "The effect of wind loads on the attainable ship speed on seaways," in Towards Green Marine Technology and Transport, C. Soares, Guedes, R. Dejhalla, and D. Pavletić, Eds. Taylor \& Francis Group, London, 2015, pp. 867-873.

[2] IMO, "Prevention of Air Pollution from Ships, IMO GHG study. MEPC 63 and 64. International Maritime Organization.," 2012.

[3] IMO, "PREVENTION OF AIR POLLUTION FROM SHIPS Opportunities for Reducing Greenhouse Gas Emissions from Ships. MEPC 58/INF.21. International Maritime Organization," 2008.

[4] Q. Meng, Y. Du, and Y. Wang, "Shipping log data based container ship fuel efficiency modeling," vol. 83, pp. 207-229, 2016.

[5] R. Vettor and C. Guedes Soares, "Detection and analysis of the main routes of voluntary observing ships in the North Atlantic," J. Navig., vol. 68, no. 2, pp. 397-410, 2015. https://doi.org/10.1017/S0373463314000757

[6] R. Vettor and C. Guedes Soares, "Multi-objective evolutionary algorithm in ship route optimization," Marit. Technol. Eng. - Proc. MARTECH 2014 2nd Int. Conf. Marit. Technol. Eng., pp. 865-876, 2015.

[7] J. Prpić-Oršić and O. M. Faltinsen, "Estimation of ship speed loss and associated CO 2 emissions in a seaway," Ocean Eng., vol. 44, pp. 1-10, 2012. https://doi.org/10.1016/j.oceaneng.2012.01.028

[8] J. Prpić-Oršić, R. Vettor, O. M. Faltinsen, and C. Guedes Soares, "The influence of route choice and operating conditions on fuel consumption and $\mathrm{CO} 2$ emission of ships," $J$. Mar. Sci. Technol., pp. 1-24, 2016. https://doi.org/10.1007/s00773-015-0367-5

[9] M. R. Haddara and C. Guedes Soares, "Wind loads on marine structures," Mar. Struct., vol. 12, no. 3, pp. 199-209, 1999. https://doi.org/10.1016/S0951-8339(99)00023-4

[10] S. Sutulo and C. Guedes Soares, "Development of a core mathematical model for arbitrary manoeuvres of a shuttle tanker," Phys. Procedia, vol. 51, pp. 293-308, 2015.

[11] M. Lącki, "Neuroevolutionary Ship Handling System in a Windy Environment," in International Journal on Marine Navigation and Safety of Sea Transportation - 
TransNav2012, 2012, no. Vol. 6(4), pp. 453-458.

[12] T. Szelangiewicz, B. Wiśniewski, and Ż. Katarzyna, "The influence of wind, wave and loading condition on total resistance and speed of the vessel," Polish Marit. Res., vol. 21, no. 3, pp. 61-67, 2014. https://doi.org/10.2478/pomr-2014-0031

[13] R. Lu, O. Turan, E. Boulougouris, C. Banks, and A. Incecik, "A semi-empirical ship operational performance prediction model for voyage optimization towards energy efficient shipping," Ocean Eng., vol. 110, no. July 2014, pp. 18-28, 2015.

[14] A. Turk and J. Prpić-Oršić, "Estimation of Extreme Wind Loads on Marine Objects," Brodogradnja, vol. 60, no. 2, pp. 147-156, 2009.

[15] N. Bialystocki and D. Konovessis, "On the estimation of ship' s fuel consumption and speed curve : A statistical approach,” J. Ocean Eng. Sci., vol. 1, no. 2, pp. 157-166, 2016. https://doi.org/10.1016/j.joes.2016.02.001

[16] M. Kim, O. Hizir, O. Turan, S. Day, and A. Incecik, "Estimation of added resistance and ship speed loss in a seaway," Ocean Eng., vol. 141, no. December 2016, pp. 465-476, 2017.

[17] R. Dallinga, M. Flikkema, and R. Grin, "Challenging wind and waves - their impact on fuel consumption. MARIN," 2008.

[18] DNV, "Rules for the Design, Construction and Inspection of Offshore Structures, Appendix A: Environmental Conditions," 1977.

[19] A. G. Davenport, "The spectrum of horizontal gustiness near the ground in high winds," Q. J. R. Meteorol. Soc., vol. 87, no. 372, pp. 194-211, 1961. https://doi.org/10.1002/qj.49708737208

[20] M. K. Ochi and V. S. Shin, "Wind Turbulent Spectra For Design Consideration Of Offshore Structures," in Offshore Technology Conference, 1988, pp. $461-467$. https://doi.org/10.4043/5736-MS

[21] API, “API-RP 2A - Recommended Practice for planning, Designing and Constructing Fixed Offshore Platforms, 19th edition," 1990.

[22] K. E. Kaasen, "Time Domain Model Representations of Standard Wind Gust Spectra," Proceedings" Ninth Int. Offs 'hore Polar Eng. Conf., vol. 11, p. 880653, 1999.

[23] DNV, "Chapter 5 - Loads," in Guideline for Offshore Structural Reliability Analysis General, 1995, pp. 100-134.

[24] A. D. Wnek, A. Paço, X. Q. Zhou, S. Sutulo, and C. Guedes Soares, "Experimental study of aerodynamic loads on an LNG carrier and floating platform," Appl. Ocean Res., vol. 51, pp. 309-319, 2015. https://doi.org/10.1016/j.apor.2015.01.009

[25] A. D. Wnek and C. Guedes Soares, "CFD assessment of the wind loads on an LNG carrier and floating platform models," Ocean Eng., vol. 97, pp. 30-36, 2015. https://doi.org/10.1016/j.oceaneng.2015.01.004

[26] I. M. V. Andersen, "Wind loads on post-panamax container ship," Ocean Eng., vol. 58, pp. 115-134, 2013. https://doi.org/10.1016/j.oceaneng.2012.10.008

[27] R. W. F. Gould, Measurements of the Wind Forces on a Series of Models of Merchant Ships. National Physical Laboratory, 1967.

[28] R. W. F. Gould, The Estimation of Wind Loads on Ship Superstructures. Royal Institution of Naval Architects, 1982.

[29] R. M. Isherwood, "Wind resistance of merchant ships," Trans. R. Inst. Nav. Archit., vol. 115, pp. 327-338, 1972.

[30] W. Blendermann, "Parameter identification of wind loads on ships," J. Wind Eng. Ind. Aerodyn., vol. 51, no. 3, pp. 339-351, 1994. https://doi.org/10.1016/0167$\underline{6105(94) 90067-1}$

[31] W. Blendermann, "Estimation of wind loads on ships in wind with a strong gradient," in Proceedings of the 14th International Conference on Offshore Mechanics and Artic 
Engineering (OMAE), 1995, pp. 271-277.

[32] OCIMF, Prediction of Wind and Current Loads on VLCCs. Oil Companies International Marine Forum, 1977.

[33] M. W. C. Oosterveld and P. Van Oossanen, "Further computer-analyzed data of the Wageningen B-screw series," Int. Shipbuild. Prog., vol. 22, no. 479, p. 13, 1975.

[34] P. Y. Feng, N. Ma, and X. C. Gu, "Long-term Prediction of Speed Reduction Due to Waves and Fuel Consumption of a Ship Actual Seas," in Proceedings of the ASME 2010 29th International Conference on Ocean, Offshore and Arctic Engineering OMAE2010 June 6-11, 2010, Shanghai, China, 2010, pp. 1-10.

[35] G. J. Komen, L. Cavaleri, M. Donelan, K. Hasselmann, S. Hasselmann, and P. A. E. M. Janssen, Dynamics and Modelling of Ocean Waves. Cambridge University Press, 1994. https://doi.org/10.1017/CBO9780511628955

[36] WISE Group, L. Cavaleri, J. H. G. M. Alves, F. Ardhuin, A. Babanin, M. Banner, K. Beli-bassakis, M. Benoit, M. Donelan, J. Groeneweg, T. H. C. Herbers, P. Hwang, P. A. E. M. Janssen, T. Janssen, I. V. Lavrenov, R. Magne, J. Monbaliu, M. Onorato, V. Polnikov, D. Resio, W. E. Rogers, A. Sheremet, J. McKeeSmith, H. L. Tolman, G. van Vledder, J. Wolf, and I. Young, "Wave modelling - The state of the art," Prog. Oceanogr., vol. 75, no. 4, pp. 603-674, 2007.

[37] A. Sterl and S. Caires, "Climatology, variability and extrema of ocean waves: The webbased KNMI/ERA-40 wave atlas," Int. J. Climatol., vol. 25, no. 7, pp. 963-977, 2005. https://doi.org/10.1002/joc.1175

[38] D. P. Dee, S. M. Uppala, A. J. Simmons, P. Berrisford, P. Poli, S. Kobayashi, U. Andrae, M. A. Balmaseda, G. Balsamo, P. Bauer, P. Bechtold, A. C. M. Beljaars, L. van de Berg, J. Bidlot, N. Bormann, C. Delsol, R. Dragani, M. Fuentes, A. J. Geer, L. Haimberger, S. B. Healy, H. Hersbach, E. V. Hólm, L. Isaksen, P. Kållberg, M. Köhler, M. Matricardi, A. P. Mcnally, B. M. Monge-Sanz, J. J. Morcrette, B. K. Park, C. Peubey, P. de Rosnay, C. Tavolato, J. N. Thépaut, and F. Vitart, "The ERA-Interim reanalysis: Configuration and performance of the data assimilation system," Q. J. R. Meteorol. Soc., vol. 137, no. 656, pp. 553-597, 2011. https://doi.org/10.1002/qj.828

[39] J. Prpić-Oršić, R. Vettor, C. Guedes Soares, and O. M. Faltinsen, "Influence of ship routes on fuel consumption and CO2 emission," Marit. Technol. Eng. - Proc. MARTECH 2014 2nd Int. Conf. Marit. Technol. Eng., pp. 857-864, 2015.

[40] R. Vettor and C. Guedes Soares, "Assessment of the Storm Avoidance Effect on the Wave Climate along the Main North Atlantic Routes," J. Navig., vol. 69, no. 1, pp. 127144, 2016. https://doi.org/10.1017/S037346331500048X

$\begin{array}{lll}\text { Submitted: } & \text { 27.04.2018. } & \text { Roberto Vettor, roberto.vettor@ centec.tecnico.ulisboa.pt } \\ & \text { Centre for Marine Technology and Ocean Engineering, Instituto Superior } \\ \text { Accepted: } & \text { 02.10.2018. } & \text { Tecnico, Universidade de Lisboa, Lisbon, Portugal } \\ & \text { Jasna Prpić-Oršić, jasnapo@riteh.hr } \\ & \text { Faculty of Engineering, Rijeka, Croatia } \\ & \text { Carlos Guedes Soares, c.guedes.soares @ centec.tecnico.ulisboa.pt } \\ & \text { Centre for Marine Technology and Ocean Engineering, Instituto Superior } \\ & \text { Tecnico, Universidade de Lisboa, Lisbon, Portugal }\end{array}$

